\title{
Isolation and genetic characterization of a novel 2.2.1.2a H5N1 virus from a vaccinated meat-turkeys flock in Egypt
}

\author{
Ahmed H. Salaheldin ${ }^{1,3}$, Jutta Veits ${ }^{2}$, Hatem S. Abd El-Hamid ${ }^{4}$, Timm C. Harder ${ }^{2}$, Davud Devrishov' \\ Thomas C. Mettenleiter ${ }^{2}$, Hafez M. Hafez ${ }^{1 *}$ and Elsayed M. Abdelwhab ${ }^{2}$
}

\begin{abstract}
Background: Vaccination of poultry to control highly pathogenic avian influenza virus (HPAIV) H5N1 is used in several countries. HPAIV H5N1 of clade 2.2.1 which is endemic in Egypt has diversified into two genetic clades. Clade 2.2.1.1 represents antigenic drift variants in vaccinated commercial poultry while clade 2.2.1.2 variants are detected in humans and backyard poultry. Little is known about H5N1 infection in vaccinated turkeys under field conditions.

Case presentation: Here, we describe an HPAI H5N1 outbreak in a vaccinated meat-turkey flock in Egypt. Birds were vaccinated with inactivated H5N2 and H5N1 vaccines at 8 and 34 days of age, respectively. At $72^{\text {nd }}$ day of age (38 days post last vaccination), turkeys exhibited mild respiratory signs, cyanosis of snood and severe congestion of the internal organs. Survivors had a reduction in feed consumption and body gain. A mortality of $\sim 29 \%$ cumulated within 10 days after the onset of clinical signs. Laboratory diagnosis using RT-qPCRs revealed presence of H5N1 but was negative for $\mathrm{H} 7$ and $\mathrm{H} 9$ subtypes. A substantial antigenic drift against different serum samples from clade 2.2.1.1 and clade 2.3.4.4 was observed. Based on full genome sequence analysis the virus belonged to clade 2.2.1.2 but clustered with recent H5N1 viruses from 2015 in poultry in Israel, Gaza and Egypt in a novel subclade designated here 2.2.1.2a which is distinct from 2014/2015 2.2.1.2 viruses. These viruses possess 2.2.1.2 clade-specific genetic signatures and also mutations in the HA similar to those in clade 2.2.1.1 that enabled evasion from humoral immune response. Taken together, this manuscript describes a recent HPAI H5N1 outbreak in vaccinated meat-turkeys in Egypt after infection with a virus representing novel distinct 2.2.1.2a subclade.
\end{abstract}

Conclusions: Infection with HPAIV H5N1 in commercial turkeys resulted in significant morbidity and mortality despite of vaccination using $\mathrm{H} 5$ vaccines. The isolated virus showed antigenic drift and clustered in a novel cluster designated here 2.2.1.2a related to viruses in poultry in Israel, Gaza and Egypt. Enforcement of biosecurity and constant update of vaccine virus strains may be helpful to protect vaccinated birds and prevent spillover infection to neighbouring countries.

Keywords: Vaccinated turkeys, H5N1, Vaccination failure, Clade 2.2.1.2, Avian influenza, Egypt

\section{Background \\ Findings}

Avian influenza (AI) viruses are members of the genus influenza virus A in the family Orthomyxoviridae and possess a single-stranded RNA genome composed of eight gene segments encode at least ten viral proteins [1]. The two envelope glycoproteins hemagglutinin (HA) and

\footnotetext{
* Correspondence: hafez@vetmed.fu-berlin.de

${ }^{1}$ Institute of Poultry Diseases, Free University of Berlin, Königsweg 63, 14163

Berlin, Germany

Full list of author information is available at the end of the article
}

neuraminidase (NA) are responsible for virus attachment to and release from the host cell, respectively. HA is the main determinant of virulence and immunogenicity. The polymerase basic $(\mathrm{PB}) 1$ and 2, polymerase acidic (PA) and nucleoprotein (NP) represent the minimal replicative unit of the virus. In addition, the bicistronic matrix (M) and non-structural (NS) gene segments each encode two proteins: M1 and M2, and NS1 and nuclear export protein (NEP), respectively. Some AI viruses possess PA-x and PB1-F2 proteins encoded by a frameshift of PA and PB1 gene segments. All proteins are associated with the virion 
except the nonstructural NS1 and PB1-F2 [1]. To date, 16 HA (H1-16) and 9 NA (N1-N9) subtypes have been detected in wild birds, the natural reservoir of the virus. Transmission of AI viruses from wild birds to domestic poultry resulted in severe losses in the poultry industry and endangered human health. In contrast to the low pathogenic (LP) nature of AI in wild birds, in domestic poultry $\mathrm{H} 5$ and $\mathrm{H} 7$ viruses may shift to high pathogenic (HP) forms after the acquisition of point mutations or swapping of gene segments between different AI subtypes [2]. In 1996/1997, an HPAI H5N1 virus was generated by the reassortment of the HA and NA segments of H5N1 with internal segments from $\mathrm{H} 6 \mathrm{~N} 1$ or $\mathrm{H} 9 \mathrm{~N} 2$ viruses in live bird markets in Hong Kong [3]. Since then, the virus has evolved into 10 different phylogenetic clades (designated clade 0 to 9) and tens of subclades according to the diversity of the HA gene [4].

Turkeys play an important role in the adaptation of wildbird viruses to gallinaceous poultry. They also act as mixing vessel for the generation of reassortant viruses sharing signatures of human, avian and swine influenza viruses [5-8]. The susceptibility of turkeys to LP and HP AI viruses is higher than that of chickens and waterfowl $[9,10]$. Severe mortality has been reported in natural outbreaks due to infection with HPAIV H7N1 [9], and recently with H5N2 and H5N8 in North America [11, 12] and Germany [13]. Therefore, vaccination of turkeys with a variety of $\mathrm{H} 5$ virus vaccines was implemented in the field to protect turkeys from lethal infection by HPAIV. The frequency and time of vaccination as well as the dose of the inactivated vaccine in turkeys are mostly different from these of chickens [14]. Antigenic-drift variants represented a serious challenge for the efficacy of current vaccines in poultry. Field reports on vaccinal breaks in chicken flocks are common [15-19], whereas little is known about H5N1 in turkeys [20].

Egypt is one of the few countries with an endemic status of clade 2.2.1 HPAI H5N1 virus, which diversified into two distinct subclades designated 2.2.1.1 and 2.2.1.2. Viruses in clade 2.2.1.1 circulated in vaccinated poultry, including turkeys, from 2007 to 2014 despite intensive blanket vaccination using over 20 diverse $\mathrm{H} 5$ vaccines [21-23]. Meanwhile, clade 2.2.1.2 viruses were observed mainly in backyard birds and humans, and recently in the commercial birds. They caused severe socioeconomic losses in the poultry industry and posed a serious pandemic threat because of their affinity to human-type receptors [24, 25]. The emergence of antigenic-drift variants, improper vaccination, and or immunosuppression are commonly held responsible for vaccination failure mainly in chickens. However, no detailed data are available on turkeys [21].

In this manuscript, we described a recent outbreak with HPAI H5N1 in a vaccinated meat turkey flock at 10 weeks of age. The flock was vaccinated twice with
H5 vaccines at 8 and 34 day of age. Details on feed consumption, body weight and mortality are provided. Full genome characterization of the isolated virus in relation to the vaccine and circulating viruses were analyzed.

\section{Case Presentation}

\section{Clinical examination}

Data on the feed consumption and mean body weight per week was calculated for living birds and summarized in Fig. 1. Generally, the feed consumption was normal and increased with time. Likewise, birds had a steady increase in body weight. At weeks 10 to 12 a remarkable decrease in feed consumption and body weight was observed (Fig. 1a), when birds started exhibiting clinical signs of mild respiratory distress, sneezing and coughing accompanied with sudden onset of mortalities. High mortality started at week 10 and increased in weeks 11 and 12 then decreased at weeks 13 and 14, where 33, 288, 362, 74 and 34 birds died, respectively. A second shorter increase of mortality at week 16 was observed (Fig. 1b). The highest number of birds died between 74 and 83 days of age (Fig. 1c). Total mortality amounted to $37.1 \%$ while $29 \%$ of turkeys died within 10 days following onset of disease in the holding. Since birds had been vaccinated twice and there was no recent record of HPAIV H5N1 in that region, postmortem examination was conducted on the farm. Birds suffered severe congestion of all internal organs including lungs. The preliminary early diagnosis suggested a bacterial infection and therefore antibiotics were used to treat the flock, but without success. Emergency vaccination with live NDV vaccine was also administered via drinking water at day 73 (Table 1) due to the low anti-NDV HI titer $\left(\mathrm{GMT}=2^{4}-2^{5}\right.$; data not shown).

\section{Laboratory diagnosis}

Swab samples were inoculated into 9-day-old SPF ECE and examined by HA/HI tests and RT-PCR. All embryonated eggs died within $48 \mathrm{~h}$ post inoculation and HA test was positive from allantoic fluid. Avian influenza virus was confirmed using HI test. Samples were submitted to the FLI for further confirmation. The results of RT-qPCRs confirmed the presence of $\mathrm{H} 5 \mathrm{~N} 1$ and revealed negative results for $\mathrm{H} 7$, H9 and N2. The cross reactivity of TK16 was studied by HI test using serum samples generated against different H5 viruses as shown in Table 2 . HI titers produced by TK16 were $4-8$ fold lower than these produced by the homologous viruses in clades 2.2.1.2, 2.2 and clade 1 and 32 fold lower than those in clades 2.2.1.1 and 2.3.4.4 (Table 2). This difference in antigenic drift was not correlated with the global HA gene or protein identity ratios (Table 2 ).

\section{Sequence analysis}

Nucleotide and amino acid (aa) identities for each gene were calculated by BioEdit and manually and summarized 

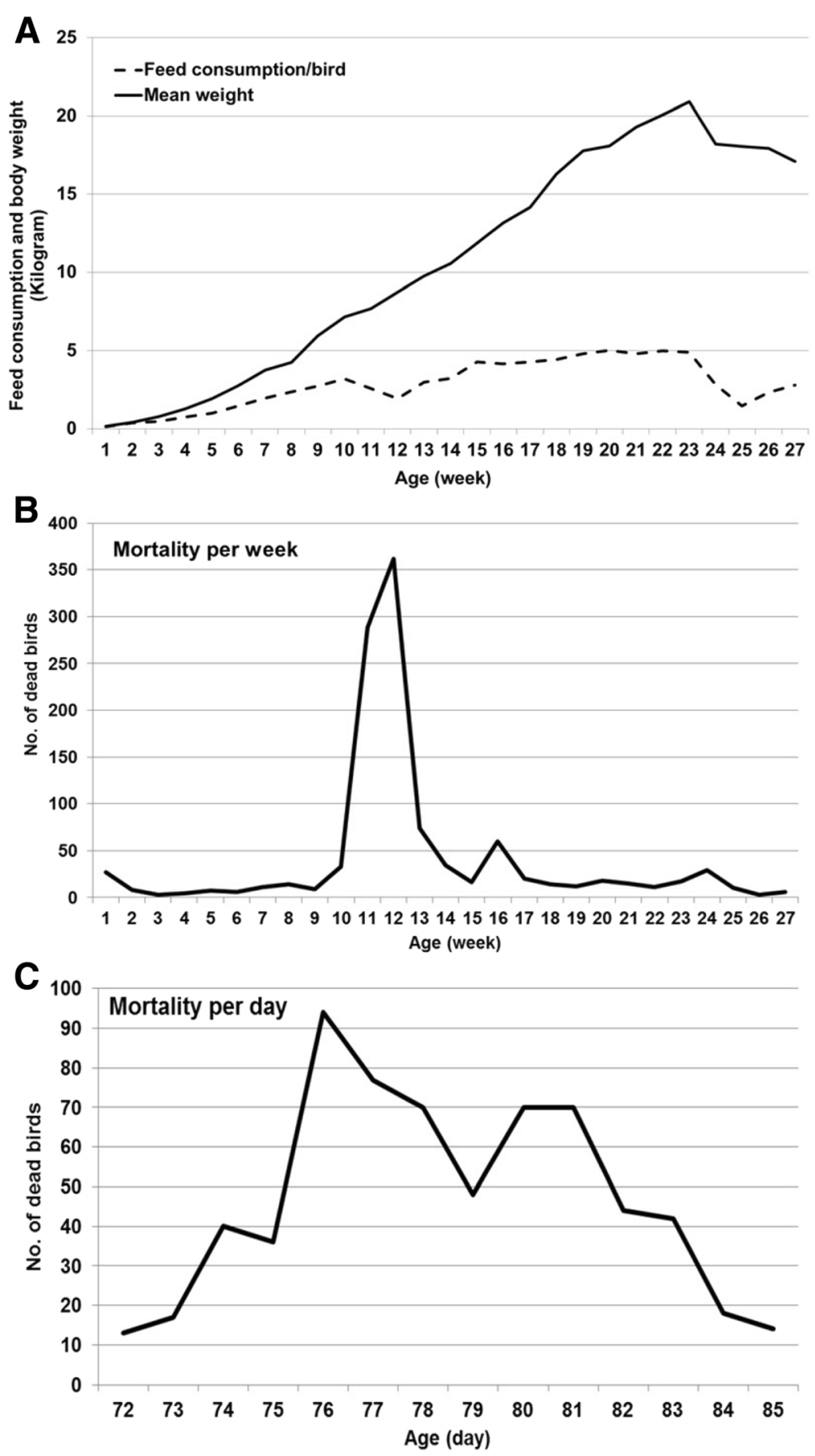

Fig. 1 Performance (a) and number of dead birds of the meat-turkey flock in this study per week (b) or per day since the appearance of clinical signs (c)

in Fig. 2, a list of mutations is supplied in Additional file 1: Table S1.

\section{Hemagglutinin (HA) gene}

The HA of TK16 shared $95.1 \%$ aa identity with the vaccine VacDK06 strain with 27 aa differences: one aa in the signal peptide, 24 aa in the HA1 and 2 aa in the HA2. These mutations are in residues $43,61,83,120,129,140$,
$141,151,155,156,162,174,181,189,227,235,252,263$, $269,272,310,322,323,325$, and 328 in the HA1 subunit, in addition to 373 and 473 in the HA2 subunit. Substitutions in residues 155 and 156 resulted in the loss of a potential glycosylation site in the head domain of TK16 (Fig. 3). The only available sequence of Mexican H5N2 virus is the HA1 which shared $83.5 \%$ aa and $78.4 \%$ nucleotide identities with the current Tk2016. Compared to 
Table 1 Vaccination program of the flock

\begin{tabular}{llll}
\hline Vaccine & Type & Age of vaccination (Day) & Route of Vaccination \\
\hline NDV (Hitchner B1)+IB & Live & 6 & Ocular \\
NDV + Al (H5N2; Mexico/94) & Inactivated & 8 & Subcutaneous \\
Avian Metapneumovirus (TRT) & Live & 15 & Ocular \\
NDV (Clone 30) & Live & 20 & Ocular \\
HE & Live & 26 & Drinking Water \\
Al (H5N1; Re-5) & Inactivated & 34 & Subcutaneous \\
Poxvirus & Live & 40 & Wing Web \\
P. multocida & Inactivated & 41 & Subcutaneous \\
NDV (Clone 30) & Live & 50 & Drinking Water \\
NDV (Lasota) & Live & 73 & Drinking Water \\
\hline
\end{tabular}

$N D=$ Newcastle Disease, $I B=$, Infectious Bronchitis, $A I=$ Avian Influenza, $T R T=$ Turkey rhinotracheitis, $H E=$ Hemorrhagic Enteritis

$\mathrm{H} 5 \mathrm{~N} 2$ vaccine is seeded by $\mathrm{A} /$ chicken/Mexico/232/CPA/94(H5N2)

Re-5 vaccine strain carry the HA and NA genes of $A /$ duck/Anhui/1/2006(H5N1)

viruses from 2006, the mature HA possessed 46 nucleotide differences, 14 out of them resulted in 11 aa changes, whereas 32 were silent. The amino acid differences are in positions 43, 120, 129, 151, 154, 155, 162, 272, 325, 373, and 537 (Fig. 3). Compared to the recent viruses in clade 2.2.1.2 from human and poultry, there was no new amino acid change but three non-synonymous mutations.

\section{Neuraminidase (NA)}

The NA of the virus shared $93.8 \%$ aa identity with the vaccine strain with 28 aa substitutions in residues 20,29 , $34,44,46,48,50,52,53,56,58,75,80,180,204,221$, $228,244,250,269,284,319,326,362,366,378,409$ and 430 (Fig. 3). The NA active and framework sites as well as the hemadsorption sites are conserved. TK16 possesses markers sensitive to the neuraminidase inhibitor Oseltamivir: V96, I97, E99, K130, D179, I203, Y233 and H255 (equivalent to N2 numbering residues 116, $117,119,150,197,222,252$ and 274, respectively). Compared to viruses from 2006 there were 16 aa differences in residues 20, 29, 34, 46, 48, 56, 74, 91, 180, 204, 221, 244, 284, 319, 378, and 430. Only 3 new mutations were found: N180S, V221I and D378E. Additionally, mutations in position $50-52$ resulted in a potential GS which was not present in the parent 2006-virus. Compared to the recent viruses in clade 2.2.1.2b, they are only different in position 46; the 2.2.1.2a possesses aspartic acid while 2.2.1.2b possesses Asparagine in addition to onenon-synonymous mutation.

\section{Other gene segments}

Identity matrices of all gene segments indicated that TK16 has $\geq 98.8$ nucleotide and aa similarity to recent poultry and human isolates in Egypt, Israel and Gaza, and up to $91 \%$ identity to the vaccine strain (Fig. 2). Compared to the parental 2006-virus and variant 2.2.1.1 clade TK16 shared $\geq 96.7$ and $\geq 95$ nucleotide and $\geq 95.1$ and $\geq 94.6$ aa identities, respectively. Mutations in TK16 compared to other viruses in Egypt and the vaccine strain are summarized in Additional file 1: Table S1. Most of mutations were similar to previous reports [2527] except in PB2 $(n=7), \mathrm{PB} 1(n=1), \mathrm{PA}(n=11), \mathrm{NP}$ $(n=4), \mathrm{M} 1(n=1), \mathrm{M} 2(n=2)$ and NS1 $(n=9)$ as shown Additional file 1: Table S1.

\section{Phylogenetic analysis}

Phylogenetic relatedness of all gene segments was determined by Bayesian inference analysis in MrBayes using

Table 2 Antigenic characterisation of A/turkey/Egypt/AR1507/2016(H5N1) (TK16) isolated from vaccinated turkeys in this study

\begin{tabular}{|c|c|c|c|c|}
\hline \multirow[t]{2}{*}{ Serum samples against: } & \multirow[t]{2}{*}{ Clade } & \multicolumn{2}{|c|}{$\mathrm{HI}$ titer $\left(\log _{2}\right)$ against } & \multirow[t]{2}{*}{ HA identity* } \\
\hline & & TK16 & Homologous antigen & \\
\hline A/chicken/Egypt/AR234-FAOF8NLQP/2014 (H5N1) & 2.2.1.2 & 7 & 9 & $99.4 / 100$ \\
\hline A/chicken/Egypt/0879-NLQP/2008 (H5N1) & 2.2.1.1 & 5 & 10 & $94.7 / 94.2$ \\
\hline A/teal/Germany/WV632/2005 (H5N1) & 2.2 & 6 & 9 & $88.7 / 90.6$ \\
\hline A/turkey/Germany-MV/R2472/2014 (H5N8) & 2.3.4.4 & 2 & 7 & $88.7 / 90.6$ \\
\hline ANietnam/1194/2004 (H5N1) & 1 & 6 & 8 & $93.2 / 95.1$ \\
\hline
\end{tabular}

HA identity ratio was calculated for nucleotides and deduced amino acids after alignment of the gene sequence and deduced amino acids using Bio Edit by the equation

100 - (Length of gene segment - Number of mutations/Length of gene segment) 


\begin{tabular}{|c|c|c|c|c|c|c|c|c|c|c|c|c|c|}
\hline HA & TK16 & IS-15 & Human-14 & CK06 & CK09 & VacDk06 & NA & TK16 & CK14 & Human-14 & CK06 & CK09 & VacDK06 \\
\hline TK16 & ID & 99.8 & 99.1 & 97 & \begin{tabular}{|l|l|}
95.4 \\
\end{tabular} & 94.1 & \begin{tabular}{|l|} 
TK16 \\
\end{tabular} & ID & 99.7 & 99.1 & 96.5 & \begin{tabular}{|l|}
95.1 \\
\end{tabular} & 93.7 \\
\hline IS-15 & 99.8 & ID & 99.2 & 96.9 & 95.1 & 93.4 & CK14 & 99.7 & ID & 99.7 & 96.8 & 95.6 & 94.3 \\
\hline Human-14 & 99.1 & 98.9 & ID & 96.6 & \begin{tabular}{|l|}
94.8 \\
\end{tabular} & 93.3 & Human-14 & 98.6 & 99.7 & ID & 96.7 & \begin{tabular}{|l|}
95.5 \\
\end{tabular} & 94.2 \\
\hline CK06 & \begin{tabular}{|l|l|} 
& 97.7 \\
\end{tabular} & 97.7 & 96.8 & ID & \begin{tabular}{|l|l|}
97.7 \\
\end{tabular} & 96.1 & CK06 & 95.9 & 96.2 & 96.4 & ID & 98.5 & 96.7 \\
\hline CK09 & 95 & 95 & 94.1 & 96.4 & ID & 94.3 & CK09 & 95.5 & 95.7 & 95.7 & 99.1 & ID & 95.9 \\
\hline VacDk06 & 94.7 & 94.7 & 94.1 & 96.1 & 93.8 & ID & VacDK06 & 93.7 & 93.9 & 93.9 & 96.2 & 95.9 & ID \\
\hline \begin{tabular}{|l|} 
PB2 \\
\end{tabular} & TK16 & CK14 & Human-14 & CK06 & CK09 & VacDK06 & PB1 & TK16 & Human-14 & \begin{tabular}{l|l}
4 & CK12 \\
\end{tabular} & CK06 & CK09 & VacDK06 \\
\hline \begin{tabular}{|l|} 
TK16 \\
\end{tabular} & ID & \begin{tabular}{|l|}
99.3 \\
\end{tabular} & 99.3 & 96.6 & 95.0 & 93.2 & TK16 & ID & 99.3 & 99 & 97.1 & 96.5 & 94.5 \\
\hline CK14 & 99.8 & ID & 99.7 & 96.8 & 95.3 & 93.3 & \begin{tabular}{|l|} 
Human-14 \\
\end{tabular} & 99.8 & ID & 99.2 & 97.3 & 96.7 & 94.8 \\
\hline Human-14 & 99.8 & 100 & ID & 96.9 & 95.4 & 93.4 & CK12 & 99.8 & 100 & ID & 97.8 & 97 & 95.3 \\
\hline СК06 & 98.2 & 98.4 & 98.4 & ID & 97.9 & 95.6 & CK06 & 99.4 & 99.6 & 99.6 & ID & 99.1 & 97.2 \\
\hline СК09 & 97.2 & 97.3 & 97.3 & 98.6 & ID & 93.7 & CK09 & 98.8 & 98.9 & 98.9 & 99.3 & ID & 96.5 \\
\hline VacDK06 & 95.3 & \begin{tabular}{|l}
95.5 \\
\end{tabular} & 95.5 & 96.5 & 95.3 & ID & \begin{tabular}{|l} 
VacDK06 \\
\end{tabular} & 98 & 98.1 & 98.1 & 98.5 & 97.8 & ID \\
\hline PA & \begin{tabular}{|l|} 
TK16 \\
\end{tabular} & CK14 & \begin{tabular}{|l|} 
Human-14 \\
\end{tabular} & \begin{tabular}{|l|} 
CK06 \\
\end{tabular} & CK09 & VacDK06 & NP & TK16 & \begin{tabular}{|l|l|} 
CK14 \\
\end{tabular} & Human-14 & CK06 & CK09 & \begin{tabular}{|l|} 
VacDK06 \\
\end{tabular} \\
\hline \begin{tabular}{|l|l|} 
TK16 \\
\end{tabular} & ID & 99.3 & 99.3 & \begin{tabular}{|l|}
97.1 \\
\end{tabular} & 96.1 & 91.0 & \begin{tabular}{|l|} 
TK16 \\
\end{tabular} & ID & 98.8 & \multirow{2}{*}{\begin{tabular}{|l|}
99.2 \\
98.7
\end{tabular}} & 96.7 & 95.9 & 95.1 \\
\hline CK14 & 98.8 & ID & 99.6 & 97.2 & 96.3 & 90.8 & CK14 & 99.3 & ID & & 97.6 & 96.8 & 95.6 \\
\hline \begin{tabular}{|l|} 
Human-14 \\
\end{tabular} & 99.0 & 99.3 & ID & 97.2 & 96.4 & 91.0 & Human-14 & 99.3 & 99.5 & ID & 96.5 & 95.7 & 94.9 \\
\hline CK06 & 97.7 & 98.0 & 98.1 & ID & 98.6 & 92.4 & CK06 & 98.3 & 98.5 & 98.1 & ID & 98.5 & 97 \\
\hline \begin{tabular}{|l|} 
CK09 \\
\end{tabular} & 97.4 & 97.9 & 97.9 & 99.5 & ID & 91.7 & \begin{tabular}{|l|} 
CK09 \\
\end{tabular} & 97.5 & 97.7 & \multirow{2}{*}{\begin{tabular}{|l|}
97.3 \\
97.5 \\
\end{tabular}} & 98.7 & ID & 95.9 \\
\hline \begin{tabular}{|l|} 
VacDK06 \\
\end{tabular} & 95.1 & 95.1 & 95.5 & 96.9 & 96.5 & ID & VacDK06 & 97.7 & 97.9 & & 98.1 & 97.5 & ID \\
\hline M1 & TK16 & CK14 & \begin{tabular}{|l|} 
Human-14 \\
\end{tabular} & CK06 & CK09 & VacDK06 & M2 & TK16 & \begin{tabular}{|l|l|} 
CK14 & $\mathrm{F}$ \\
\end{tabular} & \begin{tabular}{|l|} 
Human-14 \\
\end{tabular} & CK06 & CK099 & VacDK06 \\
\hline TK16 & ID & 99.4 & 99.7 & 98.4 & 97.6 & 97.3 & TK16 & ID & \begin{tabular}{|l|l}
97.7 & $\mathrm{~s}$ \\
\end{tabular} & 97.7 & 96.8 & 95.8 & 95.8 \\
\hline CK14 & 99.6 & ID & 99.2 & 98.6 & 97.8 & 97.8 & CK14 & 98.0 & ID & 99.3 & 98.4 & 97.4 & 96.8 \\
\hline Human-14 & 100 & 99.6 & ID & 98.1 & 97.3 & 97.3 & Human-14 & 98 & 100 & ID & 98.4 & 97.4 & 96.8 \\
\hline CK06 & 98.4 & 98.8 & 98.4 & ID & 98.9 & 98.4 & CK06 & 97.1 & \begin{tabular}{|l|l}
99.0 & $\mathrm{~s}$ \\
\end{tabular} & \multirow{2}{*}{\begin{tabular}{|l|}
99.0 \\
98.0
\end{tabular}} & ID & 98.4 & 98.4 \\
\hline СК09 & 98.4 & 98.8 & 98.4 & 99.2 & ID & 97.3 & CK09 & 96.1 & $98.0 \mathrm{C}$ & & 99.0 & ID & 97.4 \\
\hline \begin{tabular}{|l|} 
VacDK06 \\
\end{tabular} & 98.0 & 98.4 & 98.0 & 99.6 & 98.8 & ID & \begin{tabular}{|l|} 
VacDK06 \\
\end{tabular} & 97.1 & 97.1 & 97.1 & 98.0 & 97.1 & ID \\
\hline \begin{tabular}{|l|} 
NS1 \\
\end{tabular} & TK16 & CK14 & Human-14 & CK06 & CK09 & \begin{tabular}{|l|} 
VacDK06 \\
\end{tabular} & NS2 & TK16 & CK14 & \begin{tabular}{|l|} 
Human-14 \\
\end{tabular} & CK06 & CK09 & VacDK06 \\
\hline TK16 & ID & 99.7 & 99.5 & 97.0 & 96.0 & 93.7 & TK16 & ID & 99.7 & 99.7 & 97.2 & 96.4 & 94.5 \\
\hline CK14 & 100 & ID & 99.8 & 97.3 & 96.2 & 93.7 & CK14 & 100 & ID & 100 & 97.5 & 96.7 & 94.2 \\
\hline Human-14 & 100 & 100 & ID & 97.1 & 96.1 & 93.9 & Human-14 & 100 & 100 & ID & 97.5 & 96.7 & 94.2 \\
\hline CK06 & 95.1 & 95.1 & 95.1 & ID & 98.3 & 95.5 & CK06 & 99.1 & 99.1 & 99.1 & ID & 98.6 & 95.6 \\
\hline CK09 & 94.6 & 94.6 & 94.6 & 97.7 & ID & 94.2 & СК09 & 97.5 & 97.5 & 97.5 & 98.3 & ID & 94.2 \\
\hline VacDK06 & 91.1 & \begin{tabular}{|l|l}
91.1 & \\
\end{tabular} & 91.1 & 93.7 & 92.4 & ID & VacDK06 & 92.6 & 92.6 & 92.6 & 91.8 & 90.1 & ID \\
\hline $\begin{array}{l}\text { Fig. } 2 \text { Identi } \\
\text { proteins of } \mathrm{A} \\
\text { vaccine strair } \\
\mathrm{CKO6}=\mathrm{A} / \mathrm{ch} \\
\text { (clade } 2.2 .1 .1 \text { ) } \\
\text { the equation }\end{array}$ & $\begin{array}{l}\text { natrix } \\
\text { key/E } \\
16= \\
16= \\
\text { /Egy } \\
\text { d Vac } \\
\text { - - (Le }\end{array}$ & $\begin{array}{l}\text { all gen } \\
\text { t/AR15 } \\
\text { urkey/E } \\
06553-1 \\
06=\text { va } \\
\text { th of } 9\end{array}$ & $\begin{array}{l}\text { e segments } \\
07 / 2016 \text { cor } \\
\text { gypt/AR150 } \\
\text { NLQP/2006 } \\
\text { ccine strain } \\
\text { ene segmer }\end{array}$ & $\begin{array}{l}\text { de } 2.2 .1 \\
\text { luck/Ar } \\
\text { Numb }\end{array}$ & $\begin{array}{l}\text { 1), CK14 } \\
\text { nhui/1/2 } \\
\text { eer of mu }\end{array}$ & $\begin{array}{l}\text { /AR1507/20 } \\
\text { viruses of c } \\
\text { turkey/lsrael, } \\
=\text { Avchicken } \\
006 \text { (clade } \\
\text { utations/Len }\end{array}$ & $\begin{array}{l}\text { elevant H5I } \\
\text { and huma } \\
015 \text { (clade } \\
\text { /A10351A } \\
=\text { identica } \\
\text { gene segm }\end{array}$ & $\begin{array}{l}4 \text { (clac } \\
\text { lentity } \\
\text { t) }\end{array}$ & $\begin{array}{l}2.2 .1 .2), \\
\text { the nuc }\end{array}$ & $\begin{array}{l}\text { ide and amino } \\
\text { stral } 2006 \text { virus, } \\
=\mathrm{A} / \text { Egypt/MOF } \\
\text { CK09 = A/chic } \\
\text { ucleotides and }\end{array}$ & $\begin{array}{l}\text { cken/Egyp } \\
\text { amino ac }\end{array}$ & $\begin{array}{l}\text { ntity mat } \\
\text { int 2.2.1.1 } \\
\text { 71/2014 } \\
\text { t/096 L-1 } \\
\text { ids was C }\end{array}$ & $\begin{array}{l}\text { trices of all } \\
1 \text { strain and } \\
\text { (clade 2.2.1.2), } \\
\text { NLQP/2009 } \\
\text { calculated by }\end{array}$ \\
\hline
\end{tabular}

the best fit model predicted by jModelTest. Phylogenies of all gene segments of TK16 showed similar topology. In the HA, the recent viruses in clade 2.2.1.2 grouped in three distinct subclade designated subclade A, B and C. TK16 belonged to clade 2.2.1.2a clustering with gene sequences from recent viruses isolated in 2014 and 2015 in poultry in Egypt, Gaza and Israel (Fig. 4). This new cluster is supported by a high posterior probability value and possesses 3 unique non-synonymous mutations compared to viruses in group 2.2.1.2b which were isolated in the recent upsurge in 2014/2015. Likewise, the NA was also very closely related to the available sequences of viruses isolated in poultry in Israel and Gaza forming along with viruses from poultry in 2014/2015 in Egypt a distinct cluster from human viruses in 2014/
2015. Similar topology was observed for the phylogenies of other gene segments (Additional file 2 Figure S1).

\section{Discussion}

Vaccination of domestic poultry with $\mathrm{H} 5$ vaccines has been implemented in several countries to limit the spread of H5N1 AI virus. Many studies have shown that vaccination of poultry with antigenically related vaccines protected birds from morbidity, mortality and virus excretion [28-32]. However, insufficient efficacy of the vaccines was reported after the infection with antigenic drift variants $[16,18,19]$. A recent study has also shown that $\mathrm{H} 5 \mathrm{~N} 1$ clade 7.2 viruses have not been eradicated from poultry in China through intensive vaccination [33]. In the contrast to chickens, less is known about 


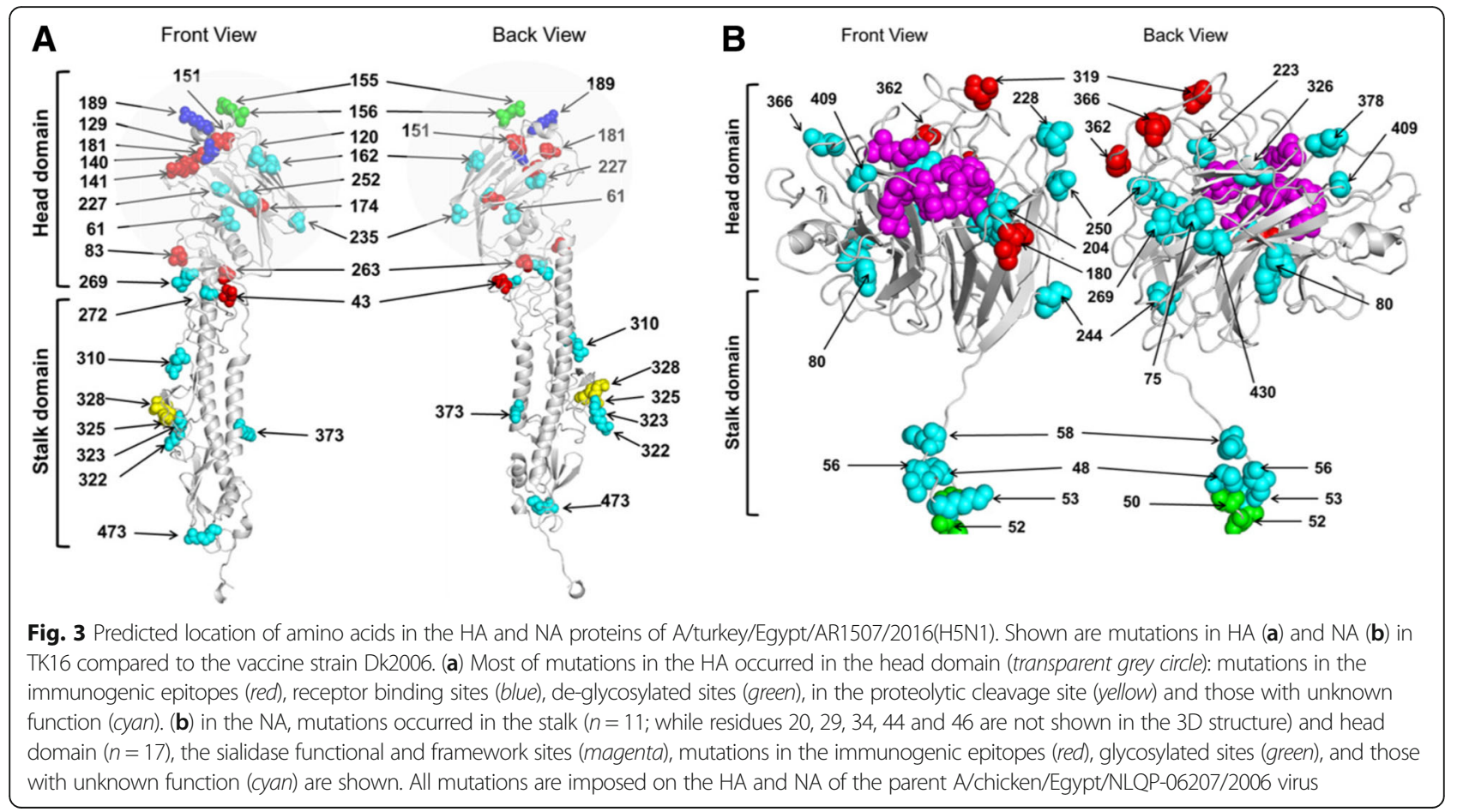

HPAI H5N1 infection in vaccinated turkeys. In this manuscript, we describe a vaccinal break in a meatturkey flock vaccinated twice with two different inactivated $\mathrm{H} 5$ vaccines. Clinical signs and sudden onset of mortality were reported few weeks after the last vaccination. Interestingly, $29 \%$ mortality within 10 days was observed and surviving turkeys showed a transient drop in feed consumption and body weight. In the available literature no data are available on the efficacy of Re-5 to protect turkeys against challenge with Egyptian H5N1like viruses. Re-5 was efficient to protect chickens from mortality after experimental infection with early $\mathrm{H} 5 \mathrm{~N} 1$ viruses in clade 2.2.1 and 2.2.1.1, although virus shedding was significantly higher than in birds vaccinated with a local vaccine [34]. In an experiment, 20 to $100 \%$ mortality during a 10 days observation period were described in turkeys vaccinated with either $\mathrm{H} 5 \mathrm{~N} 1$ or $\mathrm{H} 5 \mathrm{~N} 2$ vaccines after challenge with Egyptian HPAIV H5N1 of clade 2.2.1.1 [35].

In this study, data about the levels of anti-H5 antibodies in serum samples from the infected turkey flock are unfortunately missing. However, antigenic characterisation indicated antigenic drift particularly against serum samples from clade 2.2.1.1 in poultry in Egypt and to lesser extent against serum samples from genetically related 2.2.1.2 virus (Table 2). Also, TK16 showed remarkable antigenic drift against the recent $\mathrm{H} 5 \mathrm{~N} 8$ 2.3.4.4 viruses, descendent clade from the vaccine strain. Unlike 2.2.1.1 viruses which circulated in Egypt from 2007 to 2014, viruses in clade 2.2.1.2 showed less, if any, antigenic variation, and vaccination of chickens was efficient even with highly diverse $\mathrm{H} 5$ vaccines derived from the Egyptian viruses [34, 36]. However, TK16 showed a substantial genetic diversity at the protein level when compared with VacDK06 (clade 2.3.4) especially in HA and NA. In HA TK16 possessed up to 28 amino acids different from VacDK06. In addition to the 2.2.1.2 cladespecific signature (residues D43N, S120D, $\Delta 129 \mathrm{~S}$ I151T, R162K, G272S, R325K) which enabled efficient replication of the Egyptian 2.2.1.2 viruses in human cells and mice [24, 37, 38], several mutations in the immunogenic epitopes (L71I, I83A, R140K, S141P, D155N, A156T, V174I, P181S, T263A) [39] mostly in the HA1 head domain (Fig. 3) were observed in the new 2.2.1.2a subclade including TK2016. Some of these mutations are shared with viruses in clade 2.2.1.1 (e.g. L71I, R140K, S141P and A156T). These enabled the latter viruses to escape from the humoral immune response induced by $\mathrm{H} 5$ vaccines [40] and resulted in vaccination failure in chickens [34]. In the NA, unlike 2.2.1.1 clade viruses which contain only a single amino acid change compared to the viruses in 2006 and few mutations compared to the vaccine strains [41], clade 2.2.1.2 viruses including TK16 possess several substitutions in the NA. Residue A20, I29, I34, S44, A46, S48, S50, T52, K53, A56, and K58 are located in the stalk region [42] while the others are positioned at the head domain of the NA monomer (Fig. 3). Some amino acid changes are in the NA immunogenic epitope A (362, 366 equivalent to N2 numbering 385,389$)$, epitope B (180 equivalent to N2 


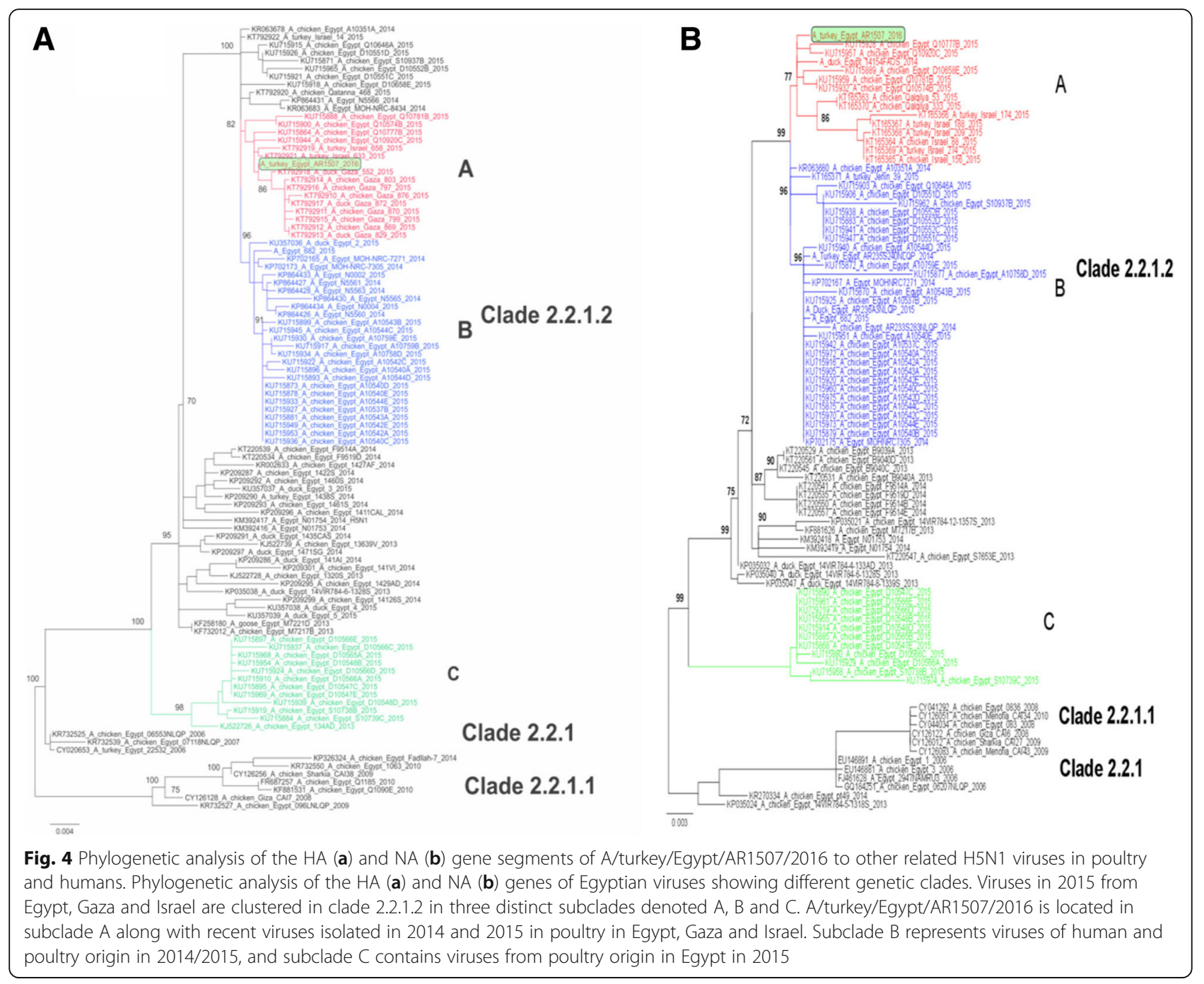

199) or epitope C (residue 319 equivalent to $339 \mathrm{~N} 2$ numbering) [43]. Meanwhile, 378 (equivalent to 402 N2 numbering) is located close to immunogenic epitope A, 204 (N2 numbering 223) close to epitope B and between two framework and functional residues of the sialidase, and 326 (equivalent to $349 \mathrm{~N} 2$ numbering) is close to epitope $C$ [43]. Together, continuous circulation of clade 2.2.1.2 viruses in vaccinated poultry resulted in the emergence of another antigenic variant sub-clade distinct from the human viruses in clade 2.2.1.2 resembling the situation in 2006 when the parental clade 2.2.1 diverged into two distinct clades: 2.2.1.1 in poultry in 2007-2014 and 2.2.1.2 in non-vaccinated poultry and humans in 2008-2016.

The source of infection in this flock is not yet clear. There was no infection in adjacent layers-flock premises according to the official reports. Since the turkey flock was vaccinated against NDV several days before starting the increased mortality the vaccination crew may be responsible for the introduction of the virus. This remains speculative, however. Moreover, phylogenetic analysis indicated a very close relationship of TK16 with recent viruses from Israel and Gaza in 2015. Since the flock was kept in an open system house, transmission by feral birds (e.g. pigeons, sparrows or egrets) or migratory birds (e.g. waterfowl) can not be excluded. Legal poultry trade between Egypt and both regions is not known and smuggling of poultry or feed is unlikely.

\section{Conclusions}

Our study is important because so far no data on the infection of vaccinated turkeys with HPAI H5N1 virus under field conditions are available. Likewise, data are scarce about performance (e.g. feed consumption and body weight) of turkeys during the course of HPAI H5N1 infection. Antigenic characterisation indicated genetic drift. Full genome analysis along with other viruses from Egypt, Israel and Gaza indicated the emergence of a new cluster supported by high posterior probability and therefore designated clade 2.2.1.2a. 
Further research is required to evaluate the efficiency of current vaccines to protect turkeys against infection with the new viruses. Also, mutations demonstrated here with unknown biological functions should be further investigated. The new cluster carries signatures from both chicken-adapted and human-adapted clades which warrants vigilance to prevent at an early stage the spread of human-adapted strains in Egypt.

\section{Methodology \\ Flock history}

The affected population was a meat-turkey flock containing 2040 male BUT-Big6 turkeys. They were reared in an open system house with good hygienic conditions. At a distance of about three-hundred meters a layer chicken farm was located. The feed was manufactured in the company feed mill supplemented by anticoccidials, anti-microbial growth promotors and antimycotoxins; all ingredients were used according to the species requirement. Water supply was from an underground source. Birds were vaccinated subcutaneously at 8 day-of age with a bivalent vaccine containing A/chicken/Mexico/CPA/1994(H5N2) and Newcastle disease virus (NDV), and boostered for AI at 34 days old using $\mathrm{Re}-5$ vaccine containing $\mathrm{HA}$ and NA from A/duck/Anhui/1/2006(H5N1) clade 2.3.4 (designated VacDK06) and other gene segments from A/Puerto Rico/1/1934(H1N1). Additionally, the flock was revaccinated and/or vaccinated against NDV, Avian Metapneumovirus (Turkey rhinotracheitisTRT), Hemorrhagic enteritis, poxvirus, and Pasteurella multocida (Table 1).

\section{Sample collection}

Cloacal and oropharyngeal swabs were collected from 25 birds at the onset of the clinical signs, or from dead birds. Swabs were placed in transport medium, consisting of phosphate-buffered saline containing glycerol, penicillin $(2000 \mathrm{U} / \mathrm{ml})$, gentamicin $(250 \mathrm{mg} / \mathrm{ml})$ and nystatin $(500 \mathrm{U} / \mathrm{ml})$. Collected swab samples were sent to the Faculty of Veterinary Medicine, Damanhur University, Egypt for routine diagnosis. Samples were also sent to the OIE and National Reference Laboratory for Avian Influenza, Federal Research Institute for Animal Health, Friedrich-Loeffler-Institut, Germany for further virus characterization. In this study, no experimental research was conducted and all turkeys were handled according to the standard guidelines.

\section{Virus isolation}

Virus isolation from swab samples was done in 9-dayold specific-pathogen-free (SPF) embryonated chicken eggs (ECE) according to the OIE guidelines [44].
Inoculated eggs were examined daily for $3-5$ days. Eggs with dead embryos were kept at $4{ }^{\circ} \mathrm{C}$ for $24 \mathrm{~h}$. Allantoic fluid was collected and examined using the standard hemagglutination test and $1 \%$ chicken erythrocytes. Allantoic fluids of positive eggs were pooled together and tested by the hemagglutination inhibition (HI) test for the presence of $\mathrm{H} 5$ and ND viruses using specific antisera [44].

\section{Antigenic characterisation}

Sera against different $\mathrm{H} 5$ viruses as well as homologous antigens were obtained from the repository of the FLI. Cross-reactivity of TK16 against different sera was studied by hemagglutination inhibition (HI) test. The HI test was done against $1 \%$ chicken erythrocytes and 4 HA units of each antigen in 96-well plastic V-bottomed microtiter plates according to the OIE manual [44]. The test was done in duplicates and the titers produced against TK16 were compared to those produced by the homologous antigens.

\section{Real-time reverse-transcription polymerase chain reaction (RT-qPCR)}

Viral RNA was extracted from swab media using the QIAamp Viral RNA Kit (Qiagen, Hilden, Germany) following the manufacturer's instructions. RT-qPCR specific for the AIV M gene was followed by RT-qPCRs specific for the HA of H5, H7, H9 HA-subtypes and N1 and N2 NA-subtypes using primers published by Hoffmann et al. [45].

\section{Sequencing and sequence analysis}

Complementary cDNA was generated from $4 \mu$ RNA using Omniscript RT Kit (Qiagen, Hilden, Germany) along with a primer specific to the conserved 12 nucleotide of 3'end of the viral RNA as previously published [46]. The HA, NP, NA, M and NS gene segments were amplified using universal primers and $1 \mu \mathrm{l}$ of cDNA according to Kreibich et al. [47], whereas the PB2, PB1 and PA genes were amplified using internal primers to generate long overlapping regions (primers are available upon request). All PCR reactions were performed in Thermocycler machine (Eppendorf, Hamburg, Germany) as previously done [47]: an initial denaturation step $\left(98^{\circ}\right.$ C 30 s), followed by 35 cycles each consisting of $98{ }^{\circ} \mathrm{C}$ 10s, $60{ }^{\circ} \mathrm{C} \mathrm{30s,} 72{ }^{\circ} \mathrm{C} 6$ min and final elongation $\left(72{ }^{\circ} \mathrm{C}\right.$ 5 min) utilizing $2 \mathrm{U}$ Phusion High-Fidelity DNA Polymerase (New England BioLabs, Frankfurt am Main, Germany) according to the manufacturer's guidelines. Fragments' sizes were determined by electrophoresis in $1 \%$ agar gel in comparison to the GeneRuler ${ }^{\text {rm }}$ DNA ladder (Thermo Scientific, Germany). Amplicons were excised and purified using the QIAquick Gel Extraction Kit (Qiagen, Hilden, Germany). The purified PCR 
products were sequenced using a BigDye Terminator v1.1 Cycle Sequencing Kit (Applied Biosystems, Langen, Germany) and appropriate primers purified with NucleoSEQ Columns (MACHEREY-NAGEL $\mathrm{GmbH} \& \mathrm{Co} . \mathrm{KG})$. Sanger sequencing was conducted in a 3130 Genetic Analyzer (Applied Biosystems). Sequences of full genome of the virus isolated in this study were submitted to the Global Initiative on Sharing All Influenza Data (GISAID) and assigned accession numbers: EPI827065 to EPI827072. N-linked glycosylation in the HA and NA proteins were predicted by NetNGlyc 1.0 Server. The location of mutations described in the HA and NA in this study was predicted on the tertiary structure of the corresponding proteins of the parent 2.2.1 virus (A/chicken/Egypt/NLQP06702/2006) using SWISS MODEL (http://swissmodel.e xpasy.org/) and then viewed and edited by geneious software suite v.8.1.3 (Biomatters, Auckland, New Zealand).

\section{Phylogenetic analysis}

Sequence similarity to each gene segment of the virus isolated in this study was detected by Basic Local Alignment Search Tool (BLAST) database available at the NCBI [48]. Sequences with the maximum BLAST scores and identity percentages were selected. Moreover, all viruses in 2014-2015 from Egypt, Israel and Gaza as well as representative viruses from clades 2.2.1 and 2.2.1.1 were downloaded. All sequences were aligned by Multiple Alignment using Fast Fourier Transform (MAFFT) [49] and further viewed and edited by BioEdit 7.1.7 [50]. Amino acid sequences were deduced from gene sequences and identity matrices were calculated using BioEdit and manually. Bayesian inference phylogenetic trees for each gene segment were generated using MrBayes 3.2.6 [51] under best-fit models calculated by jModelTest [52]. Two parallel runs consisted of four chains of Markov Chain Monte Carlo (MCMC) iterations for $10^{8}$ generations were selected for each nucleotide sequence. For each phylogenetic tree A/goose/Guangdong/1/1996(H5N1) (Clade 0) was specified as the out-group. Graphic outputs were produced by FigTree (http://tree.bio.ed.ac.uk/software/ figtree/) and Inkscape 0.91 (www.inkscape.org).

\section{Additional files}

Additional file 1: Table S1. Amino acids differences from A/turkey/ Egypt/AR1507/2016 and ancestral 2006 virus, vaccine strain and closest human isolate (DOC $36 \mathrm{~kb})$

Additional file 2: Figure S1. Phylogenetic analysis of internal protein coding gene segments of A/turkey/Egypt/AR1507/2016 to other related H5N1 viruses in poultry and humans. Phylogenetic analysis of non HA/NA genes of Egyptian viruses showing different genetic clades. Viruses in 2015 from Egypt including A/turkey/Egypt/AR1507/2016 are clustered in clade 2.2.1.2. The tree was generated by MrBayes under the best-fit model selected by jModelTest. (PDF 701 kb)

\section{Abbreviations}

aa: Amino acids; AIV: Avian influenza virus; BLAST: Basic Local Alignment Search Tool; ECE: Embryonated chicken eggs; GISAID: Global Initiative on Sharing All Influenza Data; GMT: Geometric mean titer; GS: Glycosylation site; HA test: Hemagglutination test; HA: Hemagglutinin; HI: Hemagglutination inhibition; HP: Highly pathogenic; HPAIV: Highly pathogenic avian influenza virus; LP: Low pathogenic; M: Matrix; MAFFT: Multiple Alignment using Fast Fourier Transform; MCMC: Markov Chain Monte Carlo; NA: Neuraminidase; NDV: Newcastle Disease Virus; NEP: Nuclear export protein;

NP: Nucleoprotein; NS: Non-structural; OIE: World Organisation for Animal Health; PA: Polymerase acidic; PB: Polymerase basic; RNA: Ribonucleic acid; RT-qPCRs: Real-time reverse-transcription polymerase chain reaction assays; SPF: Specific-pathogen-free; TRT: Turkey rhinotracheitis-

\section{Acknowledgments}

The authors are grateful to Dajana Helke and Diana Wessler for laboratory technical assistance and to Günter Strebelow for his assistance in sequencing. Christian Grund is thanked for providing the serum samples required for the antigenic characterisation of the virus.

\section{Funding}

This work was conducted at the Institute of Molecular Virology and Cell Biology, Friedrich-Loeffler-Institut, Federal Research Institute for Animal Health, Germany in cooperation with Institute of Poultry Diseases, Free University Berlin. AHS is supported by a doctoral scholarship funded by the Egyptian Ministry of Higher Education and EMA is supported by a grant from the Deutsche Forschungsgemeinschaft (DFG). IFT Corporation, Cairo, Egypt, is thanked for the assistance in sample shipment and for partially financing the present work. The funders had no role in study design, data collection and analysis, decision to publish, or preparation of the manuscript.

\section{Availability of data and material}

The datasets generated during and/or analysed during the current study are available from the corresponding author on reasonable request.

\section{Authors' contributions}

$A H S, J V, T C H, E M A$ amplified and sequenced the full genome of the virus, EMA, AHS analyzed the sequence and drafted the manuscript, HA, TCH, DD isolated and provided the virus, TCH, TCM, HMH revised the manuscript; all authors approved the final version of the manuscript.

\section{Competing interests}

The authors declare that they have no competing interests.

\section{Consent for publication}

Not applicable.

\section{Ethics approval}

In this study, all the experimental research was conducted and sampling of turkeys was done according to the standard guidelines of OIE.

\section{Author details}

${ }^{1}$ Institute of Poultry Diseases, Free University of Berlin, Königsweg 63, 14163 Berlin, Germany. ${ }^{2}$ Friedrich-Loeffler-Institut, Federal Research Institute for Animal Health, Suedufer 10, 17493 Insel Riems-Greifswald, Germany. ${ }^{3}$ Department of Poultry Diseases, Faculty of Veterinary Medicine, Alexandria University, Alexandria, Egypt. ${ }^{4}$ Faculty of Veterinary Medicine, Damanhur University, Damanhur, Egypt. ${ }^{5}$ Moscow State Academy of Veterinary Medicine and Biotechnology, Moscow, Russia.

Received: 29 October 2016 Accepted: 2 February 2017 Published online: 09 March 2017

\section{References}

1. Yoon SW, Webby RJ, Webster RG. Evolution and ecology of influenza a viruses. Curr Top Microbiol Immunol. 2014;385:359-75.

2. Alexander DJ. An overview of the epidemiology of avian influenza. Vaccine. 2007;25:5637-44.

3. Guan Y, Peiris JS, Lipatov AS, Ellis TM, Dyrting KC, Krauss S, Zhang LJ, Webster RG, Shortridge KF. Emergence of multiple genotypes of H5N1 
avian influenza viruses in hong Kong SAR. Proc Natl Acad Sci U S A. 2002:99:8950-5.

4. Smith GJ, Donis RO. World health organization/world organisation for animal HF, agriculture organization HEWG: nomenclature updates resulting from the evolution of avian influenza a(H5) virus clades 2.1.3.2a, 2.2.1, and 2 . 3.4 during 2013-2014. Influenza Other Respir Viruses. 2015;9:271-6.

5. Yassine HM, Al-Natour MQ, Lee CW, Saif YM. Interspecies and intraspecies transmission of triple reassortant H3N2 influenza a viruses. Virol J. 2007;4:129.

6. Pillai SP, Pantin-Jackwood M, Yassine HM, Saif YM, Lee CW. The high susceptibility of turkeys to influenza viruses of different origins implies their importance as potential intermediate hosts. Avian Dis. 2010;54:522-6.

7. Ladman BS, Driscoll CP, Pope CR, Slemons RD, Gelb Jr J. Potential of low pathogenicity avian influenza viruses of wild bird origin to establish experimental infections in turkeys and chickens. Avian Dis. 2010;54:1091-4.

8. Cilloni F, Toffan A, Giannecchini S, Clausi V, Azzi A, Capua I, Terregino C. Increased pathogenicity and shedding in chickens of a wild bird-origin low pathogenicity avian influenza virus of the H7N3 subtype following multiple in vivo passages in quail and turkey. Avian Dis. 2010;54:555-7.

9. Capua I, Mutinelli F, Marangon S, Alexander DJ. H7N1 avian influenza in Italy (1999 to 2000) in intensively reared chickens and turkeys. Avian Pathol. 2000;29:537-43.

10. Spackman E, Gelb Jr J, Preskenis LA, Ladman BS, Pope CR, Pantin-Jackwood MJ, McKinley ET. The pathogenesis of low pathogenicity H7 avian influenza viruses in chickens, ducks and turkeys. Virol J. 2010;7:331.

11. Pasick J, Berhane Y, Joseph T, Bowes V, Hisanaga T, Handel K, Alexandersen S. Reassortant highly pathogenic influenza a H5N2 virus containing gene segments related to Eurasian H5N8 in British Columbia, Canada, 2014. Sci Rep. 2015;5:9484.

12. Lee DH, Bahl J, Torchetti MK, Killian ML, Ip HS, DeLiberto TJ, Swayne DE. Highly pathogenic avian influenza viruses and generation of novel reassortants, united states, 2014-2015. Emerg Infect Dis. 2016;22:1283-5.

13. Harder T, Maurer-Stroh S, Pohlmann A, Starick E, Horeth-Bontgen D, Albrecht K, Pannwitz G, Teifke J, Gunalan V, Lee RT, et al. Influenza a(H5N8) virus similar to strain in Korea causing highly pathogenic avian influenza in Germany. Emerg Infect Dis. 2015;21:860-3.

14. Bos ME, Nielen M, Koch G, Stegeman A, De Jong MC. Effect of H7N1 vaccination on highly pathogenic avian influenza H7N7 virus transmission in turkeys. Vaccine. 2008;26:6322-8.

15. Poetri ON, Van Boven M, Claassen I, Koch G, Wibawan IW, Stegeman A, Van den Broek J, Bouma A. Silent spread of highly pathogenic avian influenza H5N1 virus amongst vaccinated commercial layers. Res Vet Sci. 2014;97:637-41.

16. El-Zoghby EF, Arafa AS, Kilany WH, Aly MM, Abdelwhab EM, Hafez HM. Isolation of avian influenza $\mathrm{H} 5 \mathrm{~N} 1$ virus from vaccinated commercial layer flock in Egypt. Virol J. 2012;9:294.

17. Long NT, Thanh $T$, van Doorn HR, Vu PP, Dung PT, Dung TT, Tien TN, Thao DT, Hung P, Quang NV, et al. Recent avian influenza virus a/H5N1 evolution in vaccinated and unvaccinated poultry from farms in southern Vietnam, january-march 2010. Transbound Emerg Dis. 2011;58:537-43.

18. Hafez MH, Arafa A, Abdelwhab EM, Selim A, Khoulosy SG, Hassan MK, Aly MM. Avian influenza $\mathrm{H} 5 \mathrm{~N} 1$ virus infections in vaccinated commercial and backyard poultry in Egypt. Poult Sci. 2010;89:1609-13.

19. Savill NJ, St Rose SG, Keeling MJ, Woolhouse ME. Silent spread of H5N1 in vaccinated poultry. Nature. 2006;442:757.

20. Parker CD, Irvine RM, Slomka MJ, Pavlidis T, Hesterberg U, Essen S, Cox B, Ceeraz V, Alexander DJ, Manvell R, et al. Outbreak of Eurasian lineage H5N1 highly pathogenic avian influenza in turkeys in great Britain in november 2007. Vet Rec. 2014;175:282.

21. Abdelwhab EM, Hassan MK, Abdel-Moneim AS, Naguib MM, Mostafa A, Hussein IT, Arafa A, Erfan AM, Kilany WH, Agour MG, et al. Introduction and enzootic of a/H5N1 in Egypt: virus evolution, pathogenicity and vaccine efficacy ten years on. Infect Genet Evol. 2016;40:80-90.

22. Aly MM, Arafa A, Hassan MK. Epidemiological findings of outbreaks of disease caused by highly pathogenic $\mathrm{H} 5 \mathrm{~N} 1$ avian influenza virus in poultry in Egypt during 2006. Avian Dis. 2008:52:269-77.

23. Abdel-Moneim AS, Shany SA, Fereidouni SR, Eid BT, El-Kady MF, Starick E, Harder T, Keil GM. Sequence diversity of the haemagglutinin open reading frame of recent highly pathogenic avian influenza $\mathrm{H} 5 \mathrm{~N} 1$ isolates from Egypt. Arch Virol. 2009;154:1559-62.

24. Watanabe Y, Ibrahim MS, Ellakany HF, Kawashita N, Mizuike R, Hiramatsu H, Sriwilaijaroen N, Takagi T, Suzuki Y, Ikuta K. Acquisition of human-type receptor binding specificity by new $\mathrm{H} 5 \mathrm{~N} 1$ influenza virus sublineages during their emergence in birds in Egypt. PLoS Pathog. 2011;7:e1002068.
25. Arafa AS, Naguib MM, Luttermann C, Selim AA, Kilany WH, Hagag N, Samy A, Abdelhalim A, Hassan MK, Abdelwhab EM, et al. Emergence of a novel cluster of influenza a(H5N1) virus clade 2.2.1.2 with putative human health impact in Egypt, 2014/15. Euro Surveill. 2015;20:2-8.

26. Naguib MM, Abdelwhab EM, Harder TC. Evolutionary features of influenza a/ H5N1 virus populations in Egypt: poultry and human health implications. Arch Virol. 2016;161:1963-7.

27. El-Shesheny R, Kandeil A, Bagato O, Maatouq AM, Moatasim Y, Rubrum A, Song MS, Webby RJ, Ali MA, Kayali G. Molecular characterization of avian influenza $\mathrm{H} 5 \mathrm{~N} 1$ virus in Egypt and the emergence of a novel endemic subclade. J Gen Virol. 2014;95:1444-63.

28. $\mathrm{Li} \mathrm{C}, \mathrm{Bu} \mathrm{Z}$, Chen H. Avian influenza vaccines against H5N1 'bird flu'. Trends Biotechnol. 2014;32:147-56.

29. Kapczynski DR, Dorsey K, Chrzastek K, Moraes M, Jackwood M, Hilt D, Gardin Y. Vaccine protection of turkeys against H5N1 highly pathogenic avian influenza virus with a recombinant turkey herpesvirus expressing the hemagglutinin gene of avian influenza. Avian Dis. 2016;60:413-7.

30. Tian G, Zeng X, Li Y, Shi J, Chen H. Protective efficacy of the H5 inactivated vaccine against different highly pathogenic $\mathrm{H} 5 \mathrm{~N} 1$ avian influenza viruses isolated in china and Vietnam. Avian Dis. 2010;54:287-9.

31. Zeng $X$, Chen P, Liu L, Deng G, Li Y, Shi J, Kong H, Feng H, Bai J, Li X, et al. Protective efficacy of an $\mathrm{H} 5 \mathrm{~N} 1$ inactivated vaccine against challenge with lethal H5N1, H5N2, H5N6, and H5N8 influenza viruses in chickens. Avian Dis. 2016;60:253-5.

32. Zeng X, Deng G, Liu L, Li Y, Shi J, Chen P, Feng H, Liu J, Guo X, Mao S, et al. Protective efficacy of the inactivated H5N1 influenza vaccine Re-6 against different clades of $\mathrm{H} 5 \mathrm{~N} 1$ viruses isolated in china and the democratic People's republic of Korea. Avian Dis. 2016;60:238-40.

33. Liu LL, Zeng XY, Chen PC, Deng GH, Li YB, Shi JZ, Gu CY, Kong HH, Suzuki Y, Jiang YP, et al. Characterization of clade $7.2 \mathrm{H} 5$ avian influenza viruses that continue to circulate in chickens in china. J Virol. 2016;90:9797-805.

34. Grund C, el SM A, Arafa AS, Ziller M, Hassan MK, Aly MM, Hafez HM, Harder TC, Beer M. Highly pathogenic avian influenza virus H5N1 from Egypt escapes vaccine-induced immunity but confers clinical protection against a heterologous clade 2.2.1 Egyptian isolate. Vaccine. 2011;29:5567-73.

35. Kilany WH, Abdelwhab EM, Arafa AS, Selim A, Safwat M, Nawar AA, Erfan AM, Hassan MK, Aly MM, Hafez HM. Protective efficacy of H5 inactivated vaccines in meat turkey poults after challenge with Egyptian variant highly pathogenic avian influenza H5N1 virus. Vet Microbiol. 2011;150:28-34.

36. Abdelwhab EM, Grund C, Aly MM, Beer M, Harder TC, Hafez HM. Multiple dose vaccination with heterologous $\mathrm{H} 5 \mathrm{~N} 2$ vaccine: immune response and protection against variant clade 2.2.1 highly pathogenic avian influenza H5N1 in broiler breeder chickens. Vaccine. 2011;29:6219-25.

37. Watanabe Y, Arai Y, Daidoji T, Kawashita N, Ibrahim MS, El-Gendy Eel D, Hiramatsu H, Kubota-Koketsu R, Takagi T, Murata T, et al. Characterization of H5N1 influenza virus variants with hemagglutinin mutations isolated from patients. MBio. 2015;6(2).

38. Schmier S, Mostafa A, Haarmann T, Bannert N, Ziebuhr J, Veljkovic V, Dietrich U, Pleschka S. In silico prediction and experimental confirmation of HA residues conferring enhanced human receptor specificity of H5N1 influenza a viruses. Sci Rep. 2015;5:11434.

39. Durvuri VR, Duvvuri B, Cuff WR, Wu GE, Wu J. Role of positive selection pressure on the evolution of $\mathrm{H} 5 \mathrm{~N} 1$ hemagglutinin. Genomics Proteomics Bioinformatics. 2009;7:47-56.

40. Cattoli G, Milani A, Temperton N, Zecchin B, Buratin A, Molesti E, Aly MM, Arafa A, Capua I. Antigenic drift in H5N1 avian influenza virus in poultry is driven by mutations in major antigenic sites of the hemagglutinin molecule analogous to those for human influenza virus. J Virol. 2011;85:8718-24.

41. Abdelwhab EM, Arafa A-S, Stech J, Grund C, Stech O, Graeber-Gerberding M, Beer M, Hassan MK, Aly MM, Harder TC, Hafez HM. Diversifying evolution of highly pathogenic H5N1 avian influenza virus in Egypt from 2006 to 2011. Virus Genes. 2012;45(23):14.

42. Munier S, Larcher T, Cormier-Aline F, Soubieux D, Su B, Guigand L, Labrosse B, Cherel Y, Quere P, Marc D, Naffakh N. A genetically engineered waterfowl influenza virus with a deletion in the stalk of the neuraminidase has increased virulence for chickens. J Virol. 2010;84:940-52.

43. Munoz ET, Deem MW. Epitope analysis for influenza vaccine design. Vaccine. 2005;23:1144-8.

44. OIE. Chapter 2.3.4. - avian influenza. 2015. Available at: http://www.oie.int/ fileadmin/Home/fr/Health_standards/tahm/2.03.04_Al.pdf. 
45. Hoffmann B, Hoffmann D, Henritzi D, Beer M, Harder TC. Riems influenza a typing array (RITA): an RT-qPCR-based low density array for subtyping avian and mammalian influenza a viruses. Sci Rep. 2016;6:27211.

46. Hoffmann E, Stech J, Guan Y, Webster RG, Perez DR. Universal primer set for the full-length amplification of all influenza a viruses. Arch Virol. 2001;146:2275-89.

47. Kreibich A, Stech J, Mettenleiter TC, Stech O. Simultaneous one-tube fulllength amplification of the NA, NP, M, and NS genes of influenza a viruses for reverse genetics. J Virol Methods. 2009;159:308-10.

48. Altschul SF, Gish W, Miller W, Myers EW, Lipman DJ. Basic local alignment search tool. J Mol Biol. 1990;215:403-10.

49. Katoh K, Standley DM. MAFFT: iterative refinement and additional methods. Methods Mol Biol. 2014;1079:131-46.

50. Hall T. BioEdit: a user-friendly biological sequence alignment editor and analysis program for windows 95/98/NT. Nucleic Acids Symp Ser. 1999:41:95-8.

51. Ronquist F, Huelsenbeck JP. MrBayes 3: Bayesian phylogenetic inference under mixed models. Bioinformatics. 2003;19:1572-4.

52. Santorum JM, Darriba D, Taboada GL, Posada D. Jmodeltest.org: selection of nucleotide substitution models on the cloud. Bioinformatics. 2014;30:1310-1.

\section{Submit your next manuscript to BioMed Central} and we will help you at every step:

- We accept pre-submission inquiries

- Our selector tool helps you to find the most relevant journal

- We provide round the clock customer support

- Convenient online submission

- Thorough peer review

- Inclusion in PubMed and all major indexing services

- Maximum visibility for your research

Submit your manuscript at www.biomedcentral.com/submit 